\title{
Overcoming the classical multidrug resistance phenotype by adenoviral delivery of anti-MDR1 short hairpin RNAs and ribozymes
}

\author{
ALEXANDER KASZUBIAK ${ }^{1}$, PER SONNE HOLM $^{2}$ and HERMANN LAGE ${ }^{1}$ \\ ${ }^{1}$ Institute of Pathology, Charité Campus Mitte, Humboldt University Berlin, Schumannstr. 20/21, \\ D-10117 Berlin; ${ }^{2}$ TU Munich, Klinikum Rechts der Isar, Institute of Oncology and \\ Experimental Therapy Research, Ismaninger Str. 22, D-81675 Munich, Germany
}

Received December 11, 2006; Accepted February 5, 2007

\begin{abstract}
Simultaneous resistance of cancer cells to multiple cytotoxic drugs, multidrug resistance (MDR), is the major limitation to the successful chemotherapeutic treatment of disseminated neoplasms. The 'classical' MDR phenotype is conferred by MDR1/P-glycoprotein (MDR1/P-gp) that is expressed in almost $50 \%$ of human cancers. Recent developments in the use of small interfering RNAs for specific inhibition of gene expression have highlighted their potential use as therapeutic agents. DNA cassettes encoding RNA polymerase III promoter-driven siRNA-like short hairpin RNAs (shRNAs) allow long-term expression of therapeutic RNAs in targeted cells. A variety of viral vectors have been used to deliver such cassettes to mammalian cells. In this study, the construction of different adenoviruses for antiMDR1/P-gp shRNA delivery in different human multidrugresistant cancer cells was investigated. The efficiency of the shRNAs was compared to adenoviral delivery of an antiMDR1/P-gp ribozyme construct. It could be demonstrated that MDR1/P-gp mRNA and protein expression could be completely inhibited by adenoviral delivery of anti-MDR1/ $\mathrm{P}$-gp shRNAs. This downregulation in mRNA and protein expression was accompanied by a complete inhibition of the pump activity of MDR1/P-gp and a reversal of the multidrugresistant phenotype. By application of adenoviral encoded anti-MDR1/P-gp ribozyme construct merely weak effects on gene expression were observed. In conclusion, the data demonstrate that adenoviral delivery of shRNAs can chemosensitize human cancer cells, that adenoviral delivery of shRNAs is much more effective than adenoviral delivery of ribozymes, and that adenovirus-based vectors can be very
\end{abstract}

Correspondence to: Dr H. Lage, Institute of Pathology, Charité Campus Mitte, Humboldt University Berlin, Schumannstr. 20/21, D-10117 Berlin, Germany

E-mail: hermann.lage@charite.de

Key words: multidrug resistance, P-glycoprotein, MDR1, gene therapy, RNAi effective agents for efficient delivery of therapeutic RNA molecules.

\section{Introduction}

Resistance of cancer cells against treatment with antineoplastic agents is the major reason why chemotherapy-based treatment modalities of malignant tumors may fail. Human cancer cells can exhibit a cross-resistant phenotype against several unrelated drugs that differ widely with respect to molecular structure and target specificity. This phenomenon has been termed multidrug resistance (MDR) (1). The 'classical' MDR phenotype is characterized by a typical cross resistance pattern against natural-product anticancer agents, such as Vinca alkaloids, anthracyclines, epipodophyllotoxins, or taxanes, and the reversibility by verapamil and cyclosporin A derivatives. The underlying mechanism conferring this phenotype is the overproduction of the MDR1 gene encoded 170-kDa MDR1/ P-glycoprotein (MDR1/P-gp, ABCB1) (2), member of the superfamily of $\mathrm{ABC}$ (adenosine triphosphate binding cassette)transporters (3). MDR1/P-gp functions as a xenobiotics pump transporting a variety of toxic agents including anticancer drugs from the intracellular milieu to outside.

Low molecular weight pharmacologically active compounds may circumvent the MDR phenotype by inhibiting the efflux pump activity of MDR1/P-gp (4). However, the innate toxicities of these compounds must be carefully considered. Moreover, improved so-called second generation MDR modulators were demonstrated to induce enhanced activity of cytochrome P450 mixed-function oxidases in the liver resulting in an increased pharmacokinetic turnover of the applied anticancer drugs. Furthermore, tumor cells can acquire resistance against the applied chemosensitizers, a so-called tertiary resistance. Consequently, it is of major interest to develop alternative, less toxic and more efficient strategies to overcome MDR.

Alternative pharmacological strategies have been described for reversal of MDR. These include the inhibition of the MDR1 mRNA expression by gene therapeutic strategies. Thus, in previous studies, antisense oligodeoxynucleotides (5), hammerhead ribozymes (6,7), and chemically synthesized small interfering RNAs (siRNAs) (8) or expression cassette 
Table I. Anti-MDR1/P-gp and anti-lacZ shRNA sequences.

\begin{tabular}{llcr}
\hline shRNA & Target sequences & nt-position ${ }^{\mathrm{a}}$ & Loop \\
\hline MDR-A & 5'-GAA GGA AAA GAA ACC AAC U-3' & $499-517$ & CCACC (11) \\
MDR-C & 5'-UGU UGU CUG GAC AAG CAC U-3' & $3051-3069$ & TTCAAGAGA (27) \\
MDR-D & 5'-UGU UGU CUG GAC AAG CAC U-3' & $3051-3069$ & CCACC (11) $^{\prime}$ \\
LacZ & 5'-AAA UCG CUG AUU UGU GUA G-3' & $364872-364852$ & CGAA $^{\text {b }}$ \\
\hline
\end{tabular}

${ }^{a}$ MDR nucleotide positions correspond to the human MDR1/P-gp encoding mRNA sequence (GeneBank accession number: NM_000927.3); LacZ nucleotide position corresponds to the lacZ ß-D-galactosidase sequence of Escherichia coli K12 (GeneBank accession number:

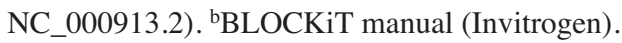

encoded short hairpin RNAs (shRNAs) (9) were shown to modulate MDR1/P-gp-dependent MDR by decreasing the expression level of the MDR1 mRNA by the RNA interference (RNAi) phenomenon, a sequence-specific gene-silencing technique with enormous potential for the development of novel gene therapeutic treatment strategies against cancer (10).

A major disadvantage in the use of chemically synthesized siRNAs is the transient effect on gene expression. Thus, for stable long-term RNAi effects, expression vectors have been developed that produce siRNA-like transcripts, short hairpin RNAs (shRNA) (11). In these vectors, commonly RNA polymerase III-specific promoters are used, e.g. H1-RNA or U6-RNA promoters. These promoters have a defined start of transcription and a termination signal consisting of five consecutive thymidines (T5), which can be used to direct the synthesis of small RNA molecules of interest lacking a poly-adenosin tail. Cleavage of the RNA transcript at the termination site is after the second uridine. Thus, the RNA polymerase III promoter produced small RNA is similar to the ends of chemically synthesized siRNAs containing two $3^{\prime}$ overhanging thymidines or uridines. The sequence of interest consists of a 19-nt sequence homologous to the target mRNA, linked with a 3- to 11-nt spacer sequence to the reverse complement of the same 19-nt target-specific sequence. The synthesized RNA transcript folds back to its complementary strand to form a 19-base pair shRNA molecule containing a spacer sequence formed loop structure. This shRNA molecule is then intracellularly processed by Dicer to a corresponding siRNA molecule and passed into the RNAi pathway (10).

Hammerhead ribozymes are small RNA molecules capable of endoribonucleolytic activity. They can be designed to target and cleave any mRNA transcript of interest (12). Thus, they represent potential molecules for the application in gene therapeutic approaches to inhibit the expression of a given transcript, e.g. the MDR1 mRNA.

A major obstacle of expression vector based gene therapy is the efficiency of delivery of the therapeutic constructs into the target cells. Although in some studies plasmid vectors are delivered into cancer cells by transfection using polymers or liposomes, virus-based strategies usually provide much higher gene delivery efficiency in most cell types. Thus, in various studies different viral vectors for delivery of shRNA encoding expression cassettes have been developed. In this study adenoviral-based vector systems were applied to improve delivery of anti-MDR1 shRNAs to different multidrug-resistant cancer cells. To compare the gene-silencing efficacy of the shRNA-based RNAi approach with alternative gene therapeutic techniques, the cells were also treated with adenoviruses expressing an anti-MDR1 hammerhead ribozyme that was characterized in detail previously $(6,7)$.

\section{Materials and methods}

Cell lines and cell culture. Establishment and cell culture of the human gastric carcinoma cell line EPG85-257P (13), and of the human pancreatic carcinoma cell line EPP85-181P (14) was described in detail previously. In both cases, 'classical' multidrug-resistant, MDR1/P-gp-positive derivatives, EPG85257RDB and EPP85-181RDB, were established by in vitro exposure to daunorubicin (Farmitalia Carlo Erba, Freiburg, Germany). These gastrointestinal cancer cell lines were grown in modified Leibovitz L15 medium (BioWhittaker, Grand Island, NY) as described previously (7-9). In order to ensure maintenance of the MDR phenotype, cell culture medium was supplemented with $4.31 \mu \mathrm{M}(2.5 \mu \mathrm{g} / \mathrm{ml})$ daunorubicin. Human kidney HEK-293 cells were cultured in Dulbecco's modified Eagle's medium (BioWhittaker) supplemented with $10 \%$ fetal calf serum, $4 \mathrm{mM} \mathrm{L}$-glutamine, and $2.5 \mathrm{mg} / \mathrm{ml}$ amphotericin B. Medium was replaced routinely twice a week.

Anti-MDRl shRNA design and construction of shRNA expression cassettes. Sequences of the used shRNAs were chosen to be homologous to anti-MDR1/P-gp siRNAs or shRNAs demonstrated for its gene-silencing activity previously $(8,9)$. For each target sequence (Table I), two complementary oligodeoxynucleotides, with four nucleotide overhangs necessary for directional cloning, were chemically synthesized (MWG Biotech, Ebersberg, Germany). Annealing was performed at a final single-stranded oligodeoxynucleotide concentration of $50 \mu \mathrm{M}$. To generate a recombination vector encoding a U6-RNA promotor-driven shRNA expression cassette, $5 \mathrm{nM}$ oligodeoxynucleotides consisting of the antiMDR1/P-gp sense sequence, a loop sequence, anti-MDR1/ $\mathrm{P}$-gp antisense sequence and the $4 \mathrm{nt} 5$ '-overhangs, were cloned into linearized recombination vector pRecU6 (pENTR/U6, Invitrogen) to generate pRecU6/MDR. The transfer of the U6-RNA-promoter-controlled shRNAs into the adenovirus 

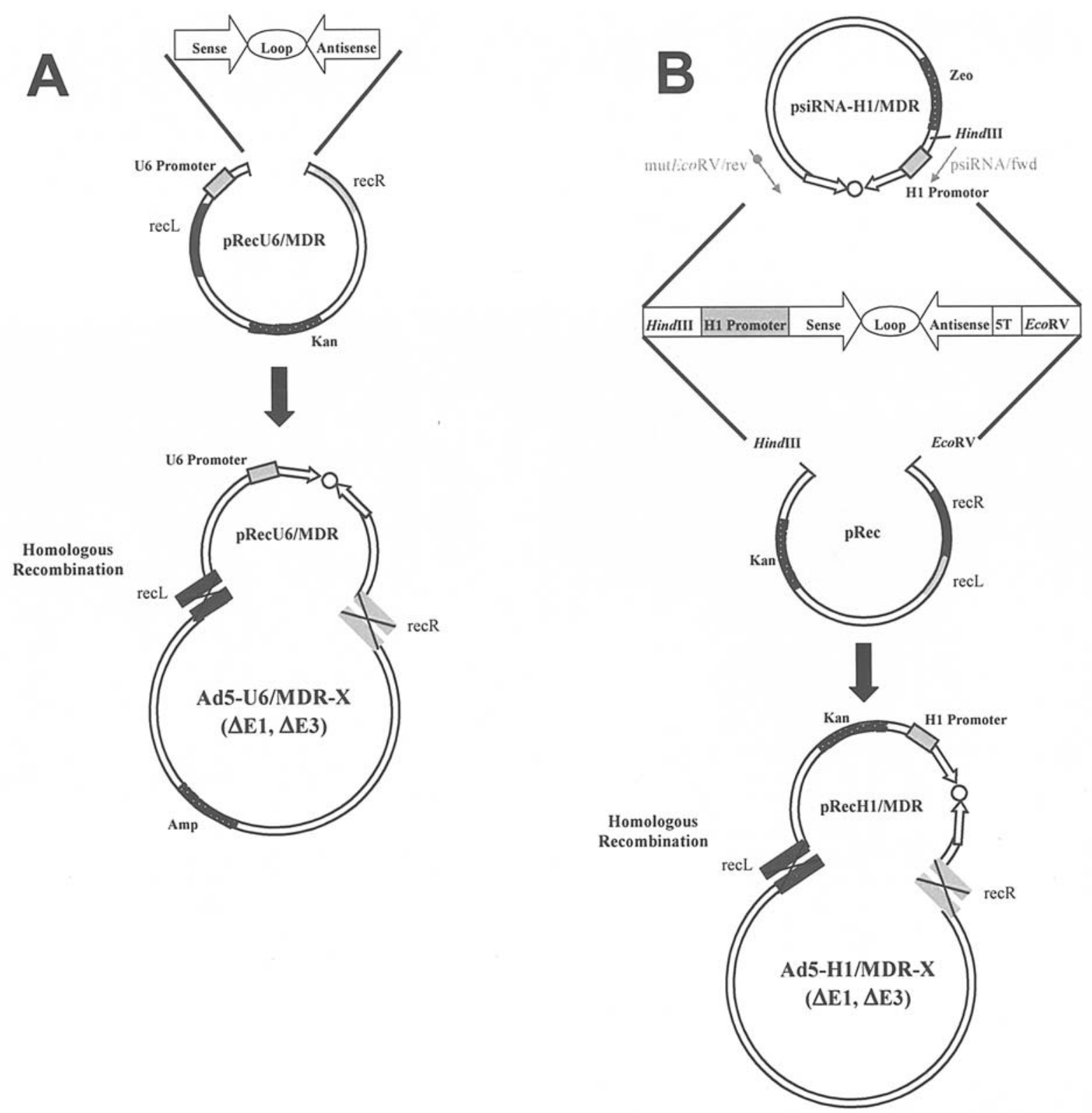

Figure 1. Construction of recombinant adenoviral vectors containing shRNA-expression cassettes driven by RNA polymerase III-depending (A) U6-RNA or (B) H1-RNA promoters; recL/recR, cassettes for site-specific recombination. By reciprocal transaction between recL and recR cassettes, oligodeoxynucleotides encoding shRNA sequences are inserted into the adenoviral backbone.

genome was performed via LR-recombination with serotype 5 first generation vector deleted for E1 and E3 using LRClonase (Invitrogen), to generate Ad5-U6/MDR-A, Ad5-U6/ MDR-C, as well as Ad5-U6/LacZ as an internal control (Fig. 1A).

H1-RNA promoter-driven shRNA expression cassettes of the vector psiRNA-hH1zeo were PCR-amplified using psiRNA/fwd (5'-GCCTCAGAAGGTACCTAACCA-3') and mutagenesis reverse primer mutEcoRV/rev (5'-TTCTTAAT CGATATCAGTAATATTTGCA-3') to generate an EcoRV restriction site. The expression cassettes were digested with $H i n d \mathrm{III}$ and EcoRV and re-cloned into the recombination vector pRecH1 (pShuttle, Stratagene) to generate pRec-H1/MDR-A and $\mathrm{pRec} / \mathrm{MDR}-\mathrm{D}$ respectively. For homologous recombination between pRec-H1/MDR, encoding for H1-RNApromotor-driven shRNAs, and the Ad5 adenoviral backbone, both vectors were electroporated into E. coli BJ5183 to generate
Ad5-H1/MDR-A and Ad5-H1/MDR-D (Fig. 1B). Sequencing of all recombinant full-length adenoviral vectors in both directions including insertion points and flanking regions were performed with AmpliTaq ${ }^{\mathrm{TM}}$ DNA Polymerase FS dye terminator cycle sequencing chemistry using the ABI PRISM ${ }^{\text {TM }}$ BigDye $^{\mathrm{TM}}$ terminator sequencing ready reaction kit (Perkin Elmer, Foster City, CA) and an automated ABI 377 sequencer (Perkin Elmer).

Anti-MDR1 ribozyme design and construction of a ribozyme expression cassette. The sequence of an anti-MDR1/P-gp hammerhead ribozyme was chosen to be identical to an antiMDR1/P-gp ribozyme demonstrated for its high gene-silencing activity previously $(6,7)$. In order to produce recombinant adenoviruses expressing this anti-MDR1/P-gp ribozyme, the oligodeoxynucleotides MDR/rib-fw 5'-TCGACGCTTGT CCACTGATGAGTCCGTGAGGACGAAACAACATTTCT 
GCA-3' and MDR/rib-rev 5'-GAAATGTTGGTTTCGTCC TCACGGACTCATCAGTGGACAAGCG-3' were hybridized and cloned into the SalI and PstI sites of the vector pGVaL (15) (kindly provided by Andre Lieber and Mark Kay, University of Washington, Seattle, USA). In a next step, the resulting vector was cleaved with $X b a \mathrm{I}$ and NheI. The fragment containing the anti-MDR 1/P-gp ribozyme under the control of the RNA polymerase III promoter Val was cloned into the $X b a \mathrm{I}$ site of the adenoviral shuttle vector $\mathrm{p} \Delta \mathrm{E} 1 \mathrm{sp} 1 \mathrm{~A}$ (16) to generate Ad5-Val/Rib. The cloned insert was verified by sequencing. Ad5-Val/Rib adenovirus particles encoding the anti-MDR1/P-gp hammerhead ribozyme were produced by cotransfection of recombinant $\mathrm{p} \Delta \mathrm{E} 1 \mathrm{sp} 1 \mathrm{~A}$ and $\mathrm{pJM} 17$ (17), which contains most of the rightward sequences of human type 5 adenovirus genome with a partial deletion in the E3 region into HEK 293 cells using calcium phosphate.

Recombinant adenovirus production. The purified shRNAexpression clones were digested with $\mathrm{PacI}$ to expose the ITRs and transfected into HEK293 using Lipofectamine reagent (Invitrogen). Adenovirus producing HEK293 cells were collected 10-11 days after transfection, and the adenoviruses were released by five freeze-thaw cycles and amplified by several reinfections in HEK293 cells. Virus preparations were characterized for replication-deficiency and insert-control by PCR. Virus was purified from HEK293 cells by three freeze/ thaw cycles prior to concentration using cesium chloride centrifugation as described previously (18), dialyzed, and stored in aliquots. Titration for determination of the viral titer of the E1A-deleted adenoviruses was made by plaque assays using HEK 293 cell monolayers.

Adenoviral infection of multidrug-resistant cancer cells. Subconfluent cells were infected $16 \mathrm{~h}$ after seeding with adenoviral vectors at various multiplicities of infection (MOI) in OptiMEM (Invitrogen) for $1 \mathrm{~h}$ at $37^{\circ} \mathrm{C}$ in a $5 \% \mathrm{CO}_{2}$ atmosphere with brief agitation every $15 \mathrm{~min}$. After infection, the medium was replaced by medium containing $10 \%$ FCS.

Confirmation of shRNA expression. For confirmation of shRNA expression in adenovirus infected cells, $5 \mu \mathrm{g}$ RNA enriched for small RNAs was prepared by using a mirVana miRNA isolation kit (Ambion), separated on $8 \%$ polyacrylamide gels, blotted to Hybond-N filter and hybridized with 10 pmol [ $\left.{ }^{32} \mathrm{P}\right]-$ 5'-phosphate labeled antisense DNA probe (5'-AGTGCTTGT CCAGACAACA-3') detecting the specific RNAi-mediating 21-nt siRNA molecules that was intracellularly processed by Dicer from the expressed shRNA molecules MDR-C and MDR-D. As control for equal RNA loading, the membranes were stripped and reprobed for detection of the 109-nt U6RNA snRNA using a ${ }^{32} \mathrm{P}-$ labeled U6-RNA DNA probe (5'TATGGAACGCTTCACGAATTTGC-3').

Confirmation of anti-MDRI hammerhead ribozyme expression. Expression of the anti-MDR hammerhead ribozyme was controlled by RT-PCR as described previously (7) using vector-specific oligodeoxynucleotide primers $\mathrm{pGVaL}-\mathrm{fw}$ (5'-TGCAAAAGGAGAGCCTGTAA-3') and RibUNIV-rev (5'-TTTCGTCCTCACGGACTCATCAG-3') yielding an expected PCR product of $200 \mathrm{bp}$ in the ribozyme-expressing cells. As positive control, oligodeoxynucleotide primers GAPDH-fwd (5'-CACCGTCAAGGCTGAGAAC-3') and GAPDH-rev (5'-ACCACTGACACGTTGGCAG-3') specific for the housekeeping gene GAPDH, were used. This RT-PCR yielded a 557-bp amplification product.

Northern blot analysis for detection of MDRI/P-gp mRNA. The amount of the MDR1/P-gp encoding mRNA was determined by Northern blot analysis applying standard procedures as described previously (7-9). In brief, total cellular RNA was prepared using an RNeasy mini kit (Qiagen). RNA (10 $\mu \mathrm{g})$ was separated on $1 \%$ agarose-formaldehyde gels and transferred onto a Hybond- $\mathrm{N}^{+}$membrane (Amersham, Aylesbury, UK). Blots were hybridized with $25 \mathrm{ng}$ of a MDR1/P-gp-encoding cDNA fragment labeled with $\left.{ }^{32} \mathrm{P}\right] \mathrm{dCTP}$ by random primed labeling (Amersham). As control for equal RNA loading the membranes were stripped and rehybridized with a fructosebisphosphate aldolase (aldolase) specific cDNA probe.

Quantitative real-time $R T$-PCR. For quantitative mRNA expression analysis, a real-time RT-PCR protocol was applied using a LightCycler instrument (Roche Diagnostics, Mannheim, Germany) as described previously $(7,8)$. For MDR1 mRNA quantification, samples were normalized against the expression of the aldolase-encoding mRNA. RNA expression data of adenovirus-treated cells were evaluated for statistical significance by the two-sided t-test.

Western blot analysis for detection of MDRI/P-gp protein. For detection of MDR1/P-gp, membrane protein extracts were prepared as described previously $(7,9)$. In brief, samples of $10 \mu \mathrm{g}$ of membrane proteins each were diluted with sample buffer and separated on $4 \%$ stacking and $7.5 \%$ resolving SDS-PA gel. Separated proteins were transferred to a $0.2-\mu \mathrm{m}$ cellulose nitrate membrane (Schleicher and Schuell, Dassel, Germany). To avoid unspecific binding, the filters were incubated in 5\% skim milk, $0.05 \%$ Tween-20 in TBS overnight. Subsequently, filters were incubated with mouse mAbs C219 (Alexis, San Diego, CA, USA) directed against human MDR1/P-gp diluted in 1\% skim milk in 1X TBST $(20 \mathrm{mM}$ Tris-Cl; $137 \mathrm{mM} \mathrm{NaCl} ; 0.05 \%$ Tween-20; pH 7.5) (1:100) for $2 \mathrm{~h}$ and, afterwards, with peroxidase-conjugated mouse anti-rabbit IgG $(1: 10,000)$ (Sigma, St. Louis, MO, USA; \#A-1949). As control for equivalent protein loading, the filters were simultaneously incubated with a mouse $\mathrm{mAb}$ directed against actin (Chemicon, Temecula, CA; \#MAB 1501R) diluted $1: 3,000$. The protein-antibody complexes were visualized by chemiluminescence (ECL system, Amersham).

Anthracycline accumulation assay. Measurement of cellular anthracycline accumulation was performed by flow cytometry as described previously $(7,9)$. In brief, $4 \times 10^{5}$ cells were seeded in six-well plates and infected with recombinant adenoviruses at MOIs of 0.5-20 on the following day. The cells were exposed to $10 \mu \mathrm{M}(5.8 \mu \mathrm{g} / \mathrm{ml})$ of daunorubicin for $1 \mathrm{~h}, 72 \mathrm{~h}$ postinfection. Cells were trypsinized, then washed twice with ice-cold phosphate-buffered saline (PBS) and analysed by FACS (Calibur 750; Becton-Dickinson, San Jose, CA). The cells were excited at $480 \mathrm{~nm}$ and emission was collected at $550 \mathrm{~nm}$. A minimum of $10^{4}$ cells was analyzed for each 


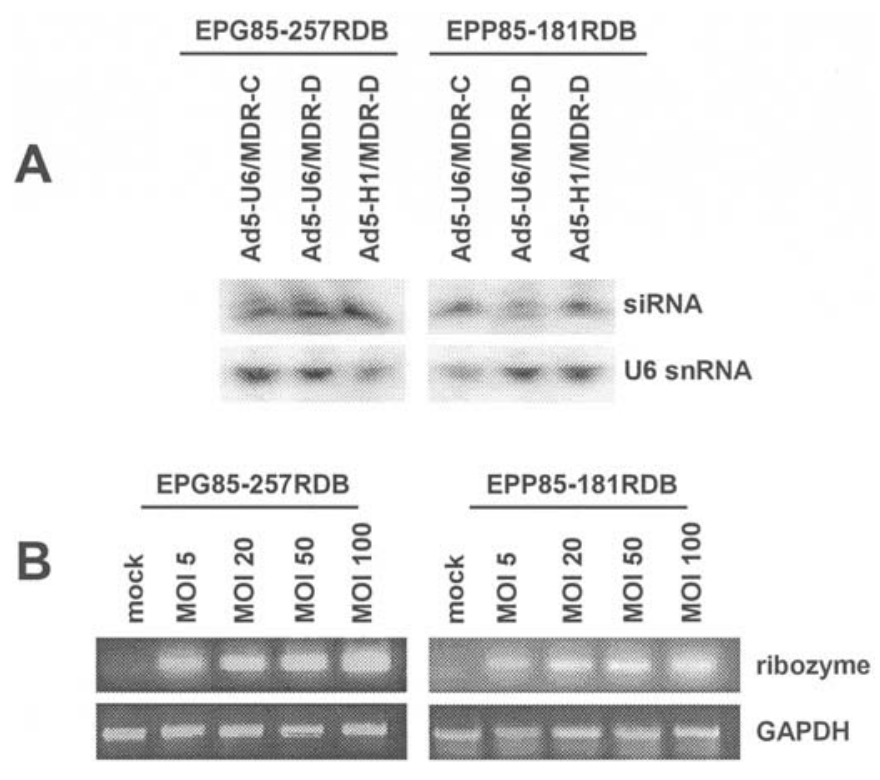

Figure 2. Confirmation of (A) shRNA, and (B) ribozyme expression in adenoviral infected multidrug-resistant carcinoma cells. For detection of cellular 21-nt siRNAs that were processed by intracellular Dicer from expressed shRNAs, $5 \mu \mathrm{g}$ of enriched small RNAs extracted from adenoviral infected (72 h after transduction at MOI 5) cell lines EPG85-257RDB and EPP85-181RDB were separated on polyacrylamide gels, blotted on membranes and hybridized with a ${ }^{32}[\mathrm{P}]$-labeled antisense oligodeoxynucleotide probe. As control, the blot was probed with a U6-RNA snRNA specific antisense oligodeoxynucleotide probe detecting the 109-nt U6-RNA snRNA. AntiMDR1-ribozyme expression was confirmed by RT-PCR using total RNA prepared from carcinoma cell lines $72 \mathrm{~h}$ after adenoviral infection at MOI 5 . As a control, a RT-PCR directed against the mRNA encoding the housekeeping enzyme GAPDH was performed.

sample. Data of at least three independent experiments in duplicate were used to calculate a geometric mean.

Cytotoxicity assay for cell survival. Chemoresistance was tested using a proliferation assay based on sulforhodamine B (SRB), a protein-binding reagent, as described previously (7-9), using $5 \times 10^{4}$ cells transduced at MOIs of 5 to 10 with anti-MDR1/P-gp- or lacZ- shRNA-expressing adenovirus in 12-well plates in triplicate. Daunorubicin, vincristine (GryPharma) or cisplatin (Gry-Pharma) were added in dilution series $48 \mathrm{~h}$ post infection. After an additional 3 days, incubation was terminated by replacing the medium with $10 \%$ trichloroacetic acid, followed by incubation at $4^{\circ} \mathrm{C}$ for $1 \mathrm{~h}$. Subsequently, the plates were washed, stained, and absorbance was measured at $562 \mathrm{~nm}$ against a background at $690 \mathrm{~nm}$. To determine the $\mathrm{IC}_{50}$ values, the absorbance difference of control cells without drug was set to be 1 . A dose-response curve was plotted by using the Prism software (GraphPad Software, Inc.; San Diego, CA, USA), and $\mathrm{IC}_{50}$ values were calculated from multiple, at least three independent experiments for each cell line.

\section{Results}

Construction of anti-MDRl shRNA and ribozyme expressing adenoviruses. To achieve a high transduction efficiency of multidrug-resistant cancer cells, recombinant adenoviruses were constructed to deliver anti-MDR1 shRNAs (Fig. 1).
Expression of the anti-MDR1 shRNAs was driven by U6RNA and H1-RNA promoters. The target sequences of the anti-MDR1 shRNAs were already demonstrated to be suitable for specific RNAi-mediated inhibition of MDR1 gene expression previously $(8,9)$. For comparison of the genesilencing efficacy of adenoviral shRNA delivery, adenoviruses expressing a well-characterized anti-MDR1 hammerhead ribozyme (9) controlled by a $\mathrm{tRNA}_{\mathrm{Val}}$ promoter were designed.

Expression of anti-MDR1 shRNA and ribozyme in adenovirusinfected carcinoma cells. The human multidrug-resistant MDR1/P-gp overexpressing cell lines EPG85-257RDB derived from gastric carcinoma and EPP85-181RDB derived from pancreatic carcinoma were transduced with different anti-MDR1 shRNA and ribozyme expressing adenoviruses. Expression of anti-MDR1 shRNAs encoded by adenoviral vectors was confirmed by Northern blot analysis detecting the corresponding specific siRNAs that were intracellularly processed by Dicer from the adenoviral encoded shRNAs (Fig. 2A). Total cellular RNA containing the anti-MDR1 siRNAs was prepared $72 \mathrm{~h}$ after transduction at multiplicity of infection (MOI) 5 and enriched for small RNAs. Expression of the anti-MDR1 hammerhead ribozyme was determined by RT-PCR analysis using vector-specific primers flanking the insertion site of the ribozyme (Fig. 2B). RT-PCR experiments using carcinoma cells expressing the anti-MDR 1 ribozyme revealed a 200-bp amplification product. RNA for RT-PCRs was prepared $72 \mathrm{~h}$ after infection with increasing MOIs of adenoviruses. Fig. 2B demonstrates that ribozyme expression levels increased in both cell systems with the number of infectious adenoviruses.

Inhibition of MDR1 mRNA expression by adenoviral shRNA delivery. The MDR cell models EPG85-257RDB and EPP85$181 \mathrm{RDB}$ were infected with shRNA encoding adenoviruses at different dosages and monitored for different time periods. In terms of time course, inhibition began 1 day after viral infection and was sustained until at least days 3 to 5 . Thus, detailed analyses of gene expression were performed 3 and 5 days after transduction. Changes in MDR1 mRNA expression were detected by Northern blot analyses. Fig. 3A-G shows a progressive reduction in MDR1 mRNA expression with increasing viral titer in both cell systems with a single exception: even MOI 100 of Ad5-U6/MDR-A did not show gene-silencing activity in EPP85-181RDB cells after 3 days (Fig. 3A). However, MOI 100 of Ad5-U6/MDR-A was efficient in the gastric carcinoma derived cell line EPG85257RDB (Fig. 3A). The H1-RNA-promoter driven variant of this virus, Ad5-H1/MDR-A, showed biological activity in both cell lines, already at MOI 50 (Fig. 3B). The most pronounced MDR1-specific gene-silencing efficacy showed Ad-U6/MDR-C in both cell systems. MOI 5 of Ad5-U6/ MDR-C had already decreased the MDR 1 transcript considerably after $72 \mathrm{~h}$ and increasing dosages of virus particles were found to have no further inhibitory effect (Fig. 3C). Five days after infection, MOI 1 was already sufficient for complete inhibition of the MDR1 transcript in both cell lines (Fig. 3D). Ad5-H1/MDR-D decreased the expression of the MDR1 mRNA in both cell systems, whereby the biological activity was more pronounced in the 

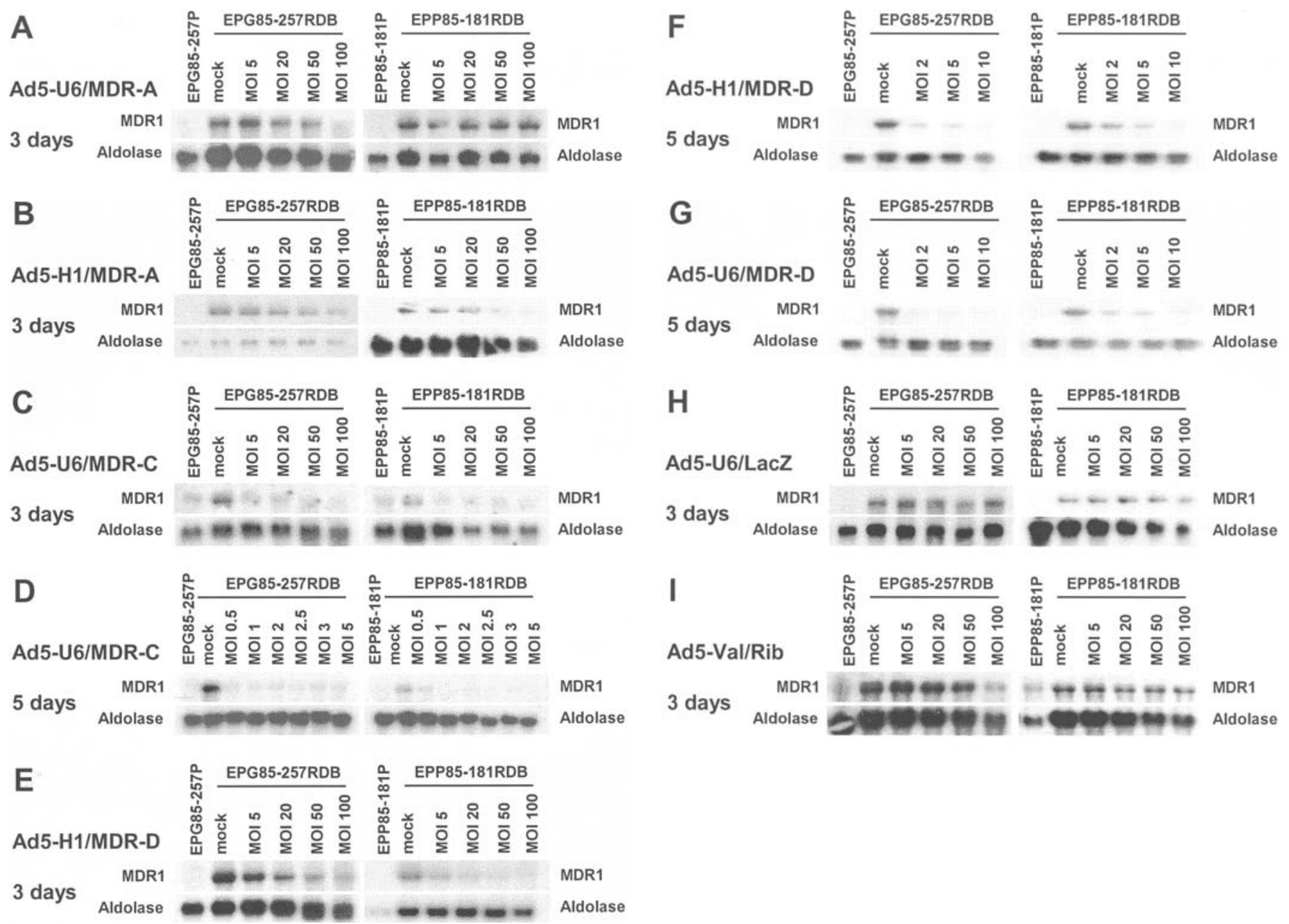

Figure 3. Northern blot analysis depicting MDR1/P-gp encoding mRNA expression in human multidrug-resistant gastric and pancreatic carcinoma cells following treatment with (A) Ad5-U6/MDR-A 3 days post infection, (B) Ad5-H1/MDR-A 3 days post infection, (C) Ad5-U6/MDR-C 3 days post infection, (D) Ad5-U6/MDR-C 5 days post infection, (E) Ad5-H1/MDR-D 3 days post infection, (F) Ad5-H1/MDR-D 5 days post infection, (G) Ad5-U6/MDR-D 5 days post infection, $(\mathrm{H})$ Ad5-U6/LacZ 3 days post infection, (I) Ad5-Val/Rib 3 days post infection. As control, the blots were probed using an aldolasespecific cDNA. EPG85-257P, drug-sensitive gastric carcinoma cells; EPG85-257RDB, MDR1/P-gp-dependent multidrug-resistant gastric carcinoma cells; EPP85-181P, drug-sensitive pancreatic carcinoma cells; EPP85-181RDB, MDR1/P-gp-dependent multidrug-resistant pancreatic carcinoma cells.

pancreatic carcinoma-derived cell model EPP85-181RDB. Three days after infection, MOI 20 was sufficient to achieve a similar gene-silencing effect in EPG85-181RDB, as was MOI 100 in the gastric carcinoma cells EPG85-257RDB (Fig. 3E). However, 5 days after transduction similar efficiencies were observed in both cell models, MOI 2 showed already high effects and MOI 10 decreased the MDR1 transcript nearly completely (Fig. 3F). The U6-RNA promoter-depending virus variant of this anti-MDR 1 shRNA construct, Ad5U6/MDR-D, likewise decreased the MDR1 mRNA expression level with high efficiency in both cell models at dosages starting with MOI 2 (Fig. 3G). Dosages up to MOI 100 of adenoviruses expressing a control shRNA directed against lacZ did not affect MDR1 mRNA expression levels (Fig. 3H). Ribozyme expressing adenoviruses appeared to have merely weak gene-silencing effects. An MOI 100 was necessary to decrease the MDR1 transcript with the ribozyme expressing virus, Ad5-Val/Rib, in gastric carcinoma EPG85-257RDB cells, whereas no effects were observed in EPP85-181RDB cells (Fig. 3I).
Quantitative MDR1 mRNA detection by real-time RT-PCR. In order to analyze the silencing effects on the MDR1 mRNA expression level of the biological most active virus construct Ad5-U6/MDR-C, a quantitative real-time RT-PCR was performed. Fig. 4 demonstrates that an increasing MOI $(0,1$, 2, and 5) of Ad5-U6/MDR-C was associated with more pronounced inhibition of MDR1 mRNA expression in both cell models, EPG85-257RDB (Fig. 4A) and EPP85-181RDB (Fig. 4B). At MOI 5 the gene-silencing effect was $77 \%$ in EPG85-257RDB gastric carcinoma cells, and 82\% in EPP85181RDB pancreatic carcinoma cells.

Inhibition of MDRI/P-gp protein expression by adenoviral shRNA delivery. For analyzing the biological effects of the antiMDR1 shRNA expressing adenoviruses on the cellular protein content, Western blot experiments were performed. Inhibition of MDR1/P-gp protein synthesis started 1-2 days after infection and was stable until at least days 3 to 5 after virus treatment. Since the mRNA expression analyses demonstrated that the shRNA encoding adenoviral vectors exhibited different bio- 

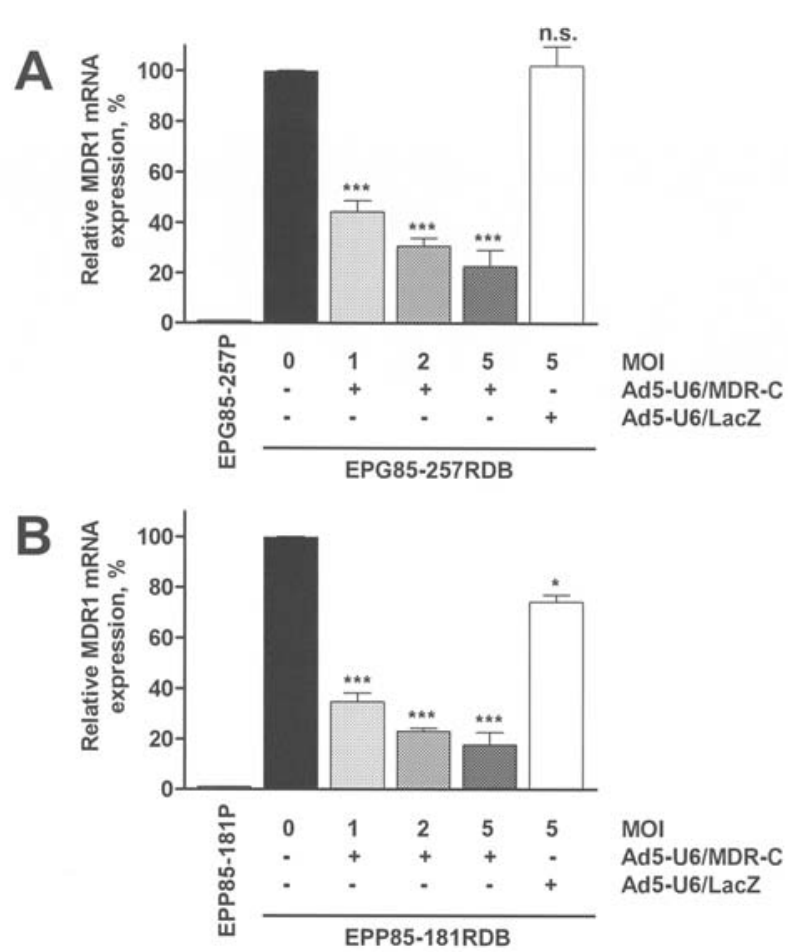

Figure 4. Analysis of RNAi-mediated silencing of MDR1 mRNA expression by quantitative real-time RT-PCR 5 days post infection with anti-MDR 1 shRNA expressing Ad5U6/MDR-C and anti-LacZ shRNA expressing adenovirus Ad5U6/LacZ, respectively. MDR1 mRNA expression levels were normalized to GAPDH mRNA expression in (A) human multidrugresistant gastric carcinoma EPG85-257RDB cells, and (B) human multidrugresistant pancreatic carcinoma EPP85-181RDB cells. EPG85-257P, drugsensitive gastric carcinoma cells; EPP85-181P, drug-sensitive pancreatic carcinoma cells; n.s., not significant; ${ }^{*} \mathrm{P}<0.1 ;{ }^{* * *} \mathrm{P}<0.001$.

logical efficiencies, merely the highly efficient viruses Ad5U6/MDR-C and Ad5-H1/MDR-D were analyzed for their effects on protein level in detail. As shown in Fig. 5A and B, MOI 1 of Ad5-U6/MDR-C was sufficient to nearly completely reduce the cellular MDR1/P-gp content after 3 and 5 days in both multidrug-resistant cell lines, EPG85-257RDB and EPP85-181RDB. These data are in line with the corresponding mRNA levels (Fig. 3B and C). Likewise on mRNA level (Fig. 3D), Ad5-H1/MDR-D decreased 3 days after virus infection the MDR1/P-gp expression level more pronounced in the pan-creatic carcinoma-derived cell model EPP85$181 \mathrm{RDB}$ than in the MDR gastric carcinoma cell line EPG85-257RDB (Fig. 5C). As expected, dosages of up to MOI 200 of adeno-viruses expressing a control shRNA directed against lacZ did not show biological effects on cellular MDR1/P-gp content 3 days after transduction (Fig. 5D). Likewise, dosages of up to MOI 100 of the ribozyme encoding virus Ad5-Val/Rib did not affect the cellular MDR1/P-gp protein amount in any of the cells (Fig. 5E).

Drug accumulation in adenovirus transduced carcinoma cells. The cellular accumulation of daunorubicin in the nonresistant, parental gastric and pancreatic carcinoma cell lines EPG85257P and EPP85-181P, and their classical MDR derivatives EPG85-257RDB and EPP85-181RDB, as well as in adenoviral transduced MDR variants was examined by flow cytometry 3 days after virus treatment. Since mRNA and protein expression
A

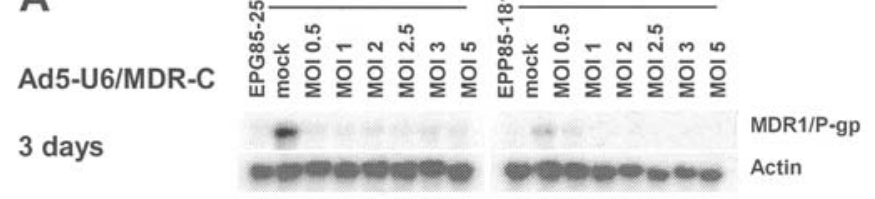

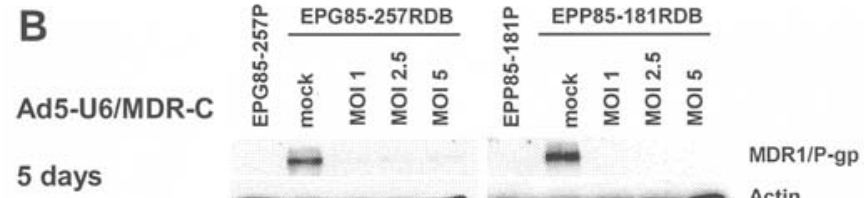

C

Ad5-H1MDR-D

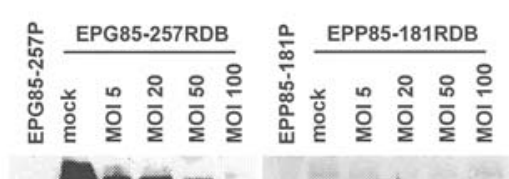

3 days

D

Ad5-U6/LacZ

3 days

E

Ad5-Val/Rib

3 days

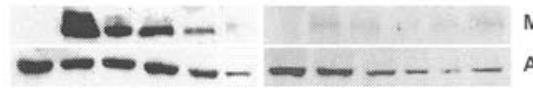

MDR1/P-gp Actin
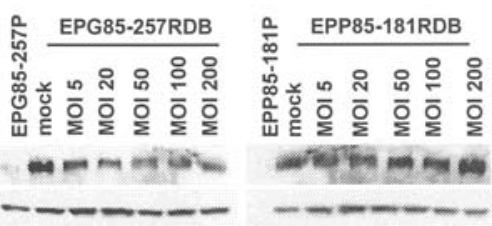

MDR1/P-gp Actin

Figure 5. Western blot analysis of cell membranous MDR1/P-gp content following treatment with (A) Ad5-U6/MDR-C 3 days post infection, (B) Ad5-U6/MDR-C 5 days post infection, (C) Ad5-H1MDR-D 3 days post infection, (D) Ad5-U6/LacZ 3 days post infection, and (E) Ad5-Val/Rib 3 days post infection. As control for equivalent protein loading, Western blot membranes were incubated with an actin-specific mAb. EPG85-257P, drug-sensitive gastric carcinoma cells; EPG85-257RDB, MDR1/P-gpdependent multidrug-resistant gastric carcinoma cells; EPP85-181P, drugsensitive pancreatic carcinoma cells; EPP85-181RDB, MDR1/P-gp-dependent multidrug-resistant pancreatic carcinoma cells.

analyses demonstrated that the shRNA encoding adenoviral vectors exhibited different gene-silencing efficiencies, merely the highly efficient virus Ad5-U6/MDR-C and for comparison Ad5-U6/MDR-A and Ad5-U6/MDR-D, as well as the control virus Ad5-U6/LacZ were used for detailed investigation of drug accumulation. In each case, increasing virus dosages from MOI 5 to 20 were used for anthracycline accumulation assays. Measuring of cellular drug accumulation demonstrated a clear dosage-depending increasing drug accumulation rate in both MDR cell models (Fig. 6A-H). As expected, the most efficient gene-silencing virus Ad5-U6/MDR6 showed the most pronounced biological activity. At MOI 20, Ad5-U6/ MDR-6 had already completely (100\%) restored the cellular drug accumulation in both formerly multidrug-resistant cell lines when compared to the respective parental counterpart $(\mathrm{P}<0.001$ in EPG85-257RDB; $\mathrm{P}<0.001$ in EPP85-181RDB) (Fig. 6C and D). At these dosages, Ad5-U6/MDR-A (Fig. 6A and B) and Ad5-U6/MDR-D (Fig. 6E and F) showed much less influence on both MDR cell variants $(30 \%$ restoration 

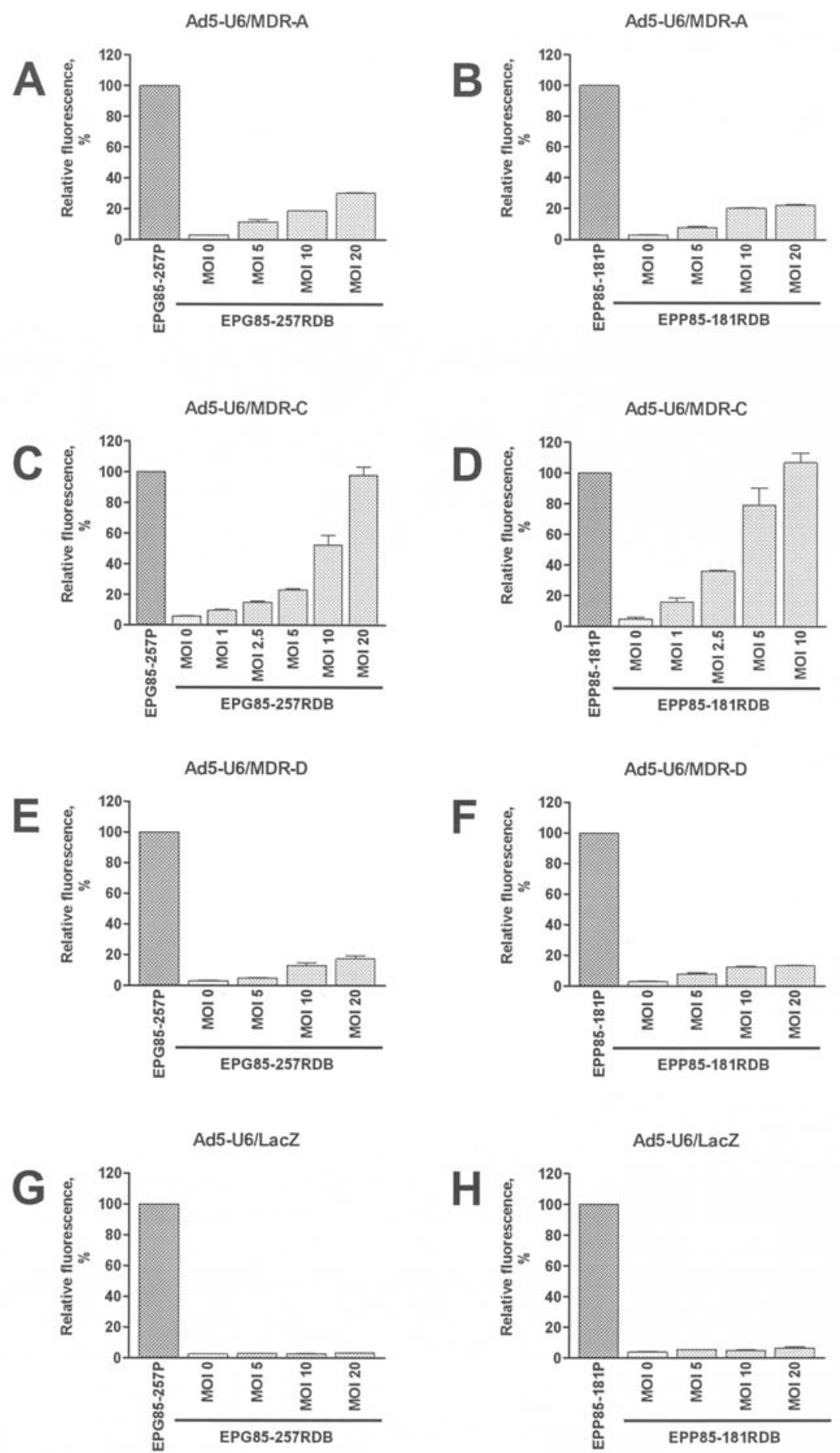

Figure 6. Daunorubicin accumulation in multidrug-resistant gastric carcinoma cells EPG85-257RDB and their drug-sensitive parental counterpart EPG85257P following 3 days of treatment with (A) Ad5-U6/MDR-A, (C) Ad5-U6/MDR-C, (E) Ad5-U6/MDR-D, and (G) Ad5-U6/LacZ; as well as daunorubicin accumulation in multidrug-resistant pancreatic carcinoma cells EPP85-181RDB and their drug-sensitive parental counterpart EPP85-181P following 3 days of treatment with (B) Ad5-U6/MDR-A, (D) Ad5-U6/MDR-C, (F) Ad5-U6/MDR-D, and (H) Ad5-U6/LacZ.

with MOI 20 Ad5-U6/MDR-A in EPG85-257RDB; 22\% restoration with MOI 20 Ad5-U6/MDR-A in EPP85-181RDB; $18 \%$ restoration with MOI 20 Ad5-U6/MDR-D in EPG85257RDB; $14 \%$ restoration with MOI 20 Ad5-U6/MDR-D in EPP85-181RDB). The control virus Ad5-U6/LacZ expressing a LacZ-specific shRNA molecule did not influence the cellular drug accumulation rate in any of the MDR cells (Fig. 6G and $\mathrm{H})$.
Reversal of the drug-resistant phenotype in adenovirustransduced carcinoma cells. Reversal of the multidrugresistant phenotypes of the classical MDR cell lines EPG85257RDB and EPP85-181RDB by treatment with anti-MDR1 shRNA expressing adenoviruses was assessed by comparison of the respective $\mathrm{IC}_{50}$ values determined by a monolayer cell proliferation assay. In these experiments, the multidrug-resistant gastric carcinoma cell line EPG85-257RDB was treated with 
A

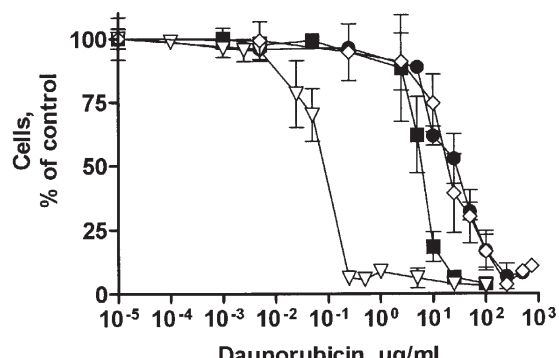

B
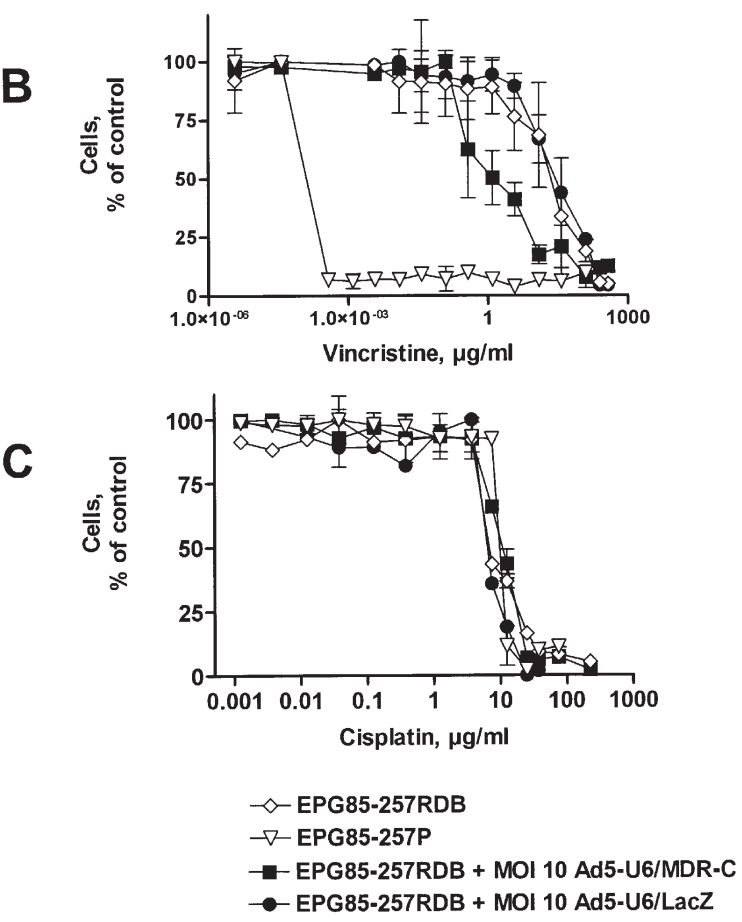
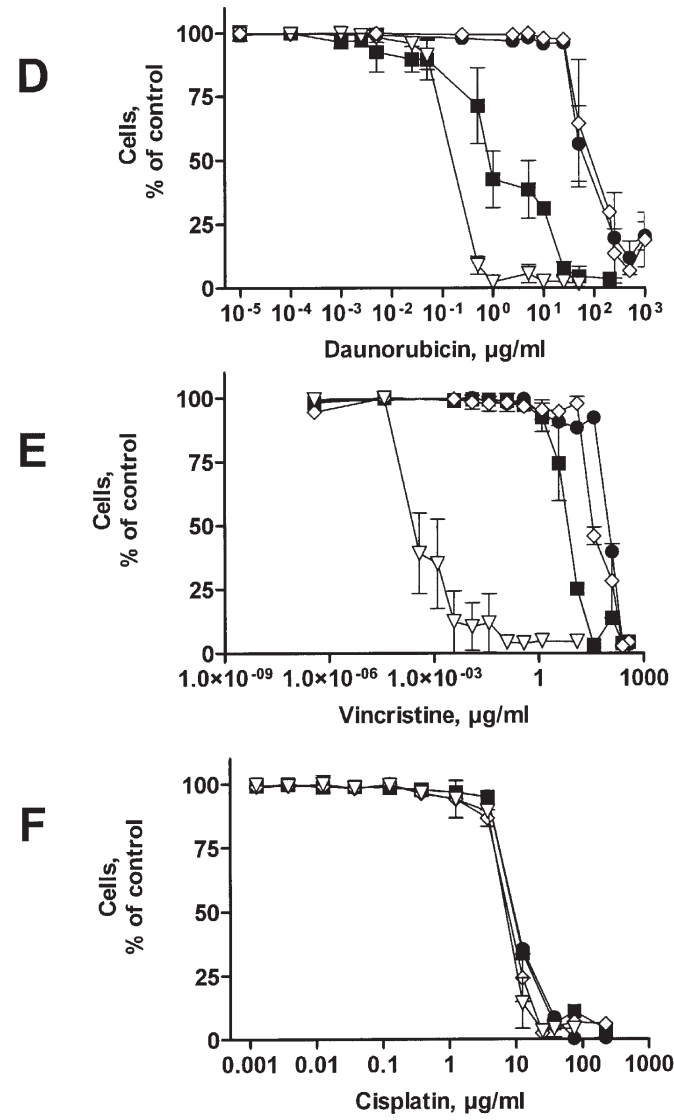

$\neg-$ EPP85-181RDB
$\rightarrow-$ EPP85-181P
$\rightarrow-$ EPP85-181RDB + MOI 10 Ad5-U6/MDR-C
$\rightarrow-$ EPP85-181RDB + MOI 10 Ad5-U6/LacZ

Figure 7. Reversal of drug resistance by the anti-MDR1/P-gp shRNA producing adenovirus Ad5U6/MDR-C as measured by a monolayer proliferation assay to assess drug-specific $\mathrm{IC}_{50}$ values. The multidrug-resistant gastric carcinoma cell line EPG85-257RDB was treated with MOI 10 of Ad5U6/MDR-C or MOI 10 of Ad5-U6/LacZ as control. (A) The daunorubicin-resistant phenotype was reversed to $>70 \%$ (P<0.01); (B) the vincristine-resistant phenotype was reversed to $>95 \%(\mathrm{P}<0.001)$; and $(\mathrm{C})$ the cisplatin-resistant phenotype was not altered. The multidrug-resistant pancreatic carcinoma cell line EPP85-181RDB was treated with MOI 5 of Ad5U6/MDR-C or MOI 5 of Ad5-U6/LacZ as control. (D) The daunorubicin-resistant phenotype was reversed to $>96 \%$ (P<0.01); (E) likewise the vincristine-resistant phenotype was reversed to $>96 \%(\mathrm{P}<0.001)$; and $(\mathrm{F})$ the cisplatin-resistant phenotype was not influenced by adenovirus treatment.

MOI 10 of the most active virus construct Ad5U6/MDR-C, or MOI 10 of Ad5-U6/LacZ as control. Using this virus dosage, the daunorubicin-resistant phenotype (Fig. 7A) of these cells was reversed to $70 \%(\mathrm{P}<0.01)$ in comparison to the parental counterpart EPG85-257P. The respective daunorubicinspecific $\mathrm{IC}_{50}$ values were measured as EPG85-257P, $\mathrm{IC}_{50}$ $=0.056 \pm 0.089 \mu \mathrm{g} / \mathrm{ml} ; \mathrm{EPG} 85-257 \mathrm{RDB}, \mathrm{IC}_{50}=14.32 \pm 25.30 \mu \mathrm{g} /$ $\mathrm{ml}$; EPG85-257RDB + MOI 10 Ad5-U6/MDR-C, $\mathrm{IC}_{50}$ $=4.912 \pm 6.673 \mu \mathrm{g} / \mathrm{ml}$; and EPG85-257RDB + MOI 10 Ad5-U6/ LacZ, $\mathrm{IC}_{50}=16.42 \pm 32.34 \mu \mathrm{g} / \mathrm{ml}$.

The vincristine-resistant phenotype (Fig. 7B) of EPG85$257 \mathrm{RDB}$ cells was reversed to $>95 \%(\mathrm{P}<0.001)$. The respective vincristine-specific $\mathrm{IC}_{50}$ values were measured as EPG85-257P, $\mathrm{IC}_{50}=0.0002824 \pm 0.000041 \mu \mathrm{g} / \mathrm{ml} ; \mathrm{EPG} 85-257 \mathrm{RDB}, \mathrm{IC}_{50}$ $=34.10 \pm 4.735 \mu \mathrm{g} / \mathrm{ml}$; EPG85-257RDB + MOI 10 Ad5-U6/ MDR-C, $\mathrm{IC}_{50}=6.224 \pm 1.09 \mu \mathrm{g} / \mathrm{ml}$; and EPG85-257RDB + MOI 10 Ad5-U6/LacZ, $\mathrm{IC}_{50}=31.94 \pm 8.275 \mu \mathrm{g} / \mathrm{ml}$.

The cisplatin-resistant phenotype (Fig. 7C) was not influenced by adenovirus treatment. The respective cisplatin- specific $\mathrm{IC}_{50}$ values were measured as EPG85-257P, $\mathrm{IC}_{50}$ $=9.462 \pm 1.2555 \mu \mathrm{g} / \mathrm{ml} ; \mathrm{EPG} 85-257 \mathrm{RDB}, \mathrm{IC}_{50}=8.603 \pm 1.421 \mu \mathrm{g} /$ $\mathrm{ml}$; EPG85-257RDB + MOI 10 Ad5-U6/MDR-C, IC $_{50}$ $=11.02 \pm 1.403 \mu \mathrm{g} / \mathrm{ml}$; and EPG85-257RDB + MOI 10 Ad5-U6/ $\mathrm{LacZ}, \mathrm{IC}_{50}=6.873 \pm 1.7315 \mu \mathrm{g} / \mathrm{ml}$;

The multidrug-resistant pancreatic carcinoma cell line EPP85-181RDB was treated with MOI 5 of Ad5U6/MDR-C, or MOI 5 of Ad5-U6/LacZ as control. In this MDR cell model, the daunorubicin-resistant phenotype (Fig. 7D) was reversed to $>96 \%(\mathrm{P}<0.01)$. The corresponding daunorubicinspecific $\mathrm{IC}_{50}$ values were determined as EPP85-181P, IC $=0.126 \pm 0.174 \mu \mathrm{g} / \mathrm{ml} ; \mathrm{EPP} 85-181 \mathrm{RDB}, \mathrm{IC}_{50}=45.76 \pm 65.52 \mu \mathrm{g} /$ $\mathrm{ml}$; EPP85-181RDB + MOI 5 Ad5-U6/MDR-C, IC 50 $=0.712 \pm 5.767 \mu \mathrm{g} / \mathrm{ml}$; and EPP85-181RDB + MOI 5 Ad5-U6/ $\mathrm{LacZ}, \mathrm{IC}_{50}=45.09 \pm 54.34 \mu \mathrm{g} / \mathrm{ml}$.

The vincristine-resistant phenotype (Fig. 7E) of EPP85181 RDB cells was reversed to $>95 \%(\mathrm{P}<0.001)$. The respective vincristin-specific $\mathrm{IC}_{50}$ values were measured as EPP85-181P, $\mathrm{IC}_{50}=0.00008487 \pm 0.000011 \mu \mathrm{g} / \mathrm{ml} ; \mathrm{EPP} 85-181 \mathrm{RDB}, \mathrm{IC}_{50}$ 
$=28.50 \pm 0.5134 \mu \mathrm{g} / \mathrm{ml} ; \mathrm{EPP} 85-181 \mathrm{RDB}+\mathrm{MOI} 10$ Ad5-U6/ MDR-C, $\mathrm{IC}_{50}=1.047 \pm 0.2571 \mu \mathrm{g} / \mathrm{ml}$; and EPP85-181RDB + MOI 10 Ad5-U6/LacZ, IC50 =35.81 $\pm 2.71 \mu \mathrm{g} / \mathrm{ml}$.

Likewise, the cisplatin-resistant phenotype (Fig. 7F) was not influenced by treatment with adenovirus. The respective cisplatin-specific $\mathrm{IC}_{50}$ values were measured as EPP85$181 \mathrm{P}, \mathrm{IC}_{50}=7.004 \pm 1.021 \mu \mathrm{g} / \mathrm{ml} ; \mathrm{EPP} 85-181 \mathrm{RDB}, \mathrm{IC}_{50}$ $=7.629 \pm 0.951 \mu \mathrm{g} / \mathrm{ml} ; \mathrm{EPP} 85-181 \mathrm{RDB}+\mathrm{MOI} 10$ Ad5-U6/ MDR-C, $\mathrm{IC}_{50}=9.609 \pm 0.519 \mu \mathrm{g} / \mathrm{ml}$; and EPP85-181RDB + MOI 10 Ad5-U6/LacZ, $\mathrm{IC}_{50}=10.10 \pm 0.9045 \mu \mathrm{g} / \mathrm{ml}$.

\section{Discussion}

RNAi has become widely used as an experimental tool to analyze the function of mammalian genes. Furthermore, there is substantial interest in the possibility of utilizing the RNAi technology for gene therapeutic approaches. The efficiency of gene silencing is dependent on the number of siRNA molecules transfected into the cells and the duplexes become progressively diluted as cells divide. The persistence of siRNA activity in mammalian cells varies with the proliferative status of the cells. Further problems are the biological half-life times of the target transcript and its encoding protein. In the case of MDR1/P-gp, it was shown that the MDR1/P-gpspecific mRNA had a half-life of approximately $4 \mathrm{~h}$, and the corresponding transporter protein exhibited a half-life of approximately $16 \mathrm{~h}$ (19). Accordingly, the previous application of anti-MDR1/P-gp siRNAs in the classical multidrugresistant cell line EPG85-257RDB resulted in a maximum decrease of MDR1/P-gp mRNA expression after 1-2 days and a maximum decrease of the transporter protein after 3-5 days (8). After those minimum peak levels, the expression levels of the MDR1/P-gp encoding mRNA as well as the corresponding protein started to increase and reached the original mRNA expression levels after 7 days for the mRNA transcript and 10 days for the corresponding MDR1/P-gp protein. Thus, by transient application of the siRNA molecules used for construction of the expression vector used in this study, the MDR phenotype was merely decreased to $48-58 \%$ in EPG85-257RDB cells.

To overcome these problems, vector-based systems for the introduction and stable expression of RNAi-mediating RNAs in target cells have been developed (20). Recent study also indicates that shRNAs are more potent inducers of RNAi than siRNAs (21). Such vector systems have been successfully used to obtain efficient and stable knockdown of target genes including the MDR1/P-gp encoding gene (9). In EPG85257RDB cells, the expression of MDR1/P-gp could be stably and completely inhibited. Therewith, the utmost high multidrug resistance was completely reversed.

However, a key limitation for therapeutics based on RNAi is the ability to deliver or express these molecules efficiently in disease-relevant clinical settings. Since the use of plasmid vectors in terms of efficiency of transfection is limited, viral vector systems for shRNA delivery have been developed. In this context, adenoviral vectors have many advantages as a gene therapeutic delivery system (22). Thus, in this study adenoviral vectors were designed to improve delivery and efficacy of the RNAi strategy for MDR1/Pgp-specific gene silencing.
For expression of shRNAs, different vector systems were designed to direct the stable synthesis of shRNAs by strong RNA polymerase-II-dependent promoters such as CMV or EF1a, or by RNA polymerse-III promoters such as U6-RNA or H1-RNA (11,23-25). Since previous experiences with antisense and ribozyme technology indicate that RNA polymerase-III expression systems offer great potential in stable expression of short RNA molecules in vitro as well as in vivo (26), in this study RNA polymerase-III-driven expression vector systems were applied. For comparison of different promoters, adenoviral anti-MDR1 shRNA expression vectors contained either U6-RNA or H1-RNA promoters. These two promoters did not show significant differences in efficacy of MDR1/ $\mathrm{P}$-gp-specific gene-silencing in both multidrug-resistant cancer cell lines. Accordingly, the type of RNA polymerase-IIIspecific promoter has no impact for the design of adenoviralbased RNAi strategies against MDR1/P-gp in the used cell models.

Contradictory data are available, whether the size of the loop within the shRNA molecule has influence on the genesilencing activity. Brummelkamp et al (11) reported that a 9-nt loop showed more effects than a 7-nt loop, whereas a 5-nt loop structure showed only moderate effects. Alternative studies reported that very short loop structures including 3and 5-nt loops did not show smaller shRNA-mediated gene silencing effects than longer loops $(9,27,28)$. Our experiments in the used cell models with loop lengths of 5, 7,9 and $11 \mathrm{nt}$ demonstrated that high gene-silencing effects can be achieved with all these different loop structures and that the length of the loop has no predictive influence on the biological activity of shRNA molecules $(29,30)$. Thus, in this study merely a 5-nt (MDR-A, MDR-D) and a 9-nt (MDR-C) loop structure was chosen for construction of the vectors. Most interestingly, here it could be demonstrated that the 5-nt loop structure of Ad5-U6/MDR-C achieved more gene-silencing activity than the 9-nt loop of Ad5-U6/MDR-D, although both viruses target the same sequence and share the same promoter. Thus, the data indicate that an ideal loop structure for this approach can only be identified empirically. This implicates that in terms of therapy applications the loop structure has to be considered.

The target sequences of the adenovirus encoded anti-MDR1 shRNAs were chosen to be homologous to two MDR1/P-gp target sequences used for suppression of the MDR1/P-gp expression by siRNAs (8) or plasmid vector encoded shRNAs (9) previously. These target sequences were selected according to the recommendations in the scientific literature $(31,32)$ (MDR-A), or to be homologous to a well-assessable ribozyme cleavage site analyzed in detail previously $(6,7)$ (MDR-B). Experiments with siRNAs demonstrated that MDR-B targeting the ribozyme cleavage site was biologically more efficient than targeting the conventional siRNA target site MDR-A (8). Due to theoretical deliberations, problems may arise by using the second (MDR-B) shRNA target sequence. The MDR-B sequence contains two thymidines at the 3 '-terminus. Thus, the RNA polymerase-III-depending T5-termination signal could terminate the transcription of the MDR-B shRNA two nucleotides earlier as desired. This effect would result in a loss of the two 3'-overhanging uracils within the shRNA molecule, and therewith, in a diminished biological stability of the shRNA. This theoretical assumption was supported by 
the experimental observation that it was not possible to decrease the MDR1 expression with an MDR-B encoding shRNA expression vector, neither in EPG85-257RDB cells, nor in EPP85-181RDB cells (9).

Thus, the MDR-B sequence was modified by shifting two nucleotides downstream of the target sequence. The modified sequence (MDR-C and MDR-D; the difference is the loop structure) also targets the ribozyme cleavage site, but the corresponding shRNA will not be terminated too early like MDR-B. The adenovirus experiments performed in this study demonstrated that the shRNAs MDR-C and MDR-D directed against the ribozyme target sequence, likewise showed much more pronounced biological activity than the shRNA MDR-A directed against a conventional target site. This effect might be explained by the well-assessable secondary structure of the MDR1 mRNA in this region $(6,7)$.

The more pronounced gene-silencing effects of the MDR-B siRNA and the MDR-C and MDR-D shRNA constructs are in contradiction to the observations made by others who concluded that compared to antisense or ribozyme technology, the secondary structure of siRNA target mRNAs does not appear to have a strong effect on gene silencing (32). However, the data from this study, our previous experiments $(9,29,30)$ and others (33) indicate that in future experiments the secondary structure of the target molecule should be taken into consideration.

The considerable biological effects of adenoviral delivered anti-MDR1 shRNAs on the expression of the MDR1/P-gp encoding mRNA and the corresponding pump protein were accompanied by a complete restoration of the drug accumulation. By using the most effective adenovirus Ad5-U6/MDR-C, merely dosages of MOI 10 in pancreatic carcinoma cells and MOI 20 in gastric carcinoma cells were sufficient to achieve the same intracellular anthracycline accumulation as in the drug-sensitive, parental counterparts. These data demonstrate a very high efficacy of Ad5-U6/MDR-C mediating a complete inhibition of the biological activity of the MDR1/P-gp efflux pump and, therewith, may be considered for therapeutic utilization.

Although it was demonstrated previously that plasmidbased expression vectors encoding an anti-MDR1 hammerhead ribozyme $(6,7)$ could completely reverse the MDR phenotype in EPP85-181RDB cells, the adenoviral delivery of this catalytic active RNA molecule by Ad5-Val/Rib showed merely weak biological effects. This observation indicates that the shRNA-mediated RNAi approach may be more useful for construction of adenoviral vectors than the ribozyme-based gene-silencing approach.

This study has demonstrated that the adenoviral-based RNAi approach can be tremendously effective in reversing MDR1/P-gp-mediated MDR, even in extremely highly drugresistant cell models. It was demonstrated that the adenoviral RNAi approach was much more efficient than adenoviral delivery of different ribozyme-depending strategies for genesilencing. Thus, virus-based RNAi technology has clinical implications for the prevention and the reversal of MDR in human malignancies, and prolonging disease-free survival in certain cases by gene therapeutic approaches.

\section{Acknowledgements}

This study was funded in the RiNA network for RNA technologies by the City of Berlin and the Federal Ministry of Education and Research (BMBF) and the European Regional Development Fund and was supported by grant LA 1039/2-3 of the Deutsche Forschungsgemeinschaft (DFG). We thank Birgit Schaefer and Klaus Mantwill for their technical help.

\section{References}

1. Biedler JL and Riehm H: Cellular resistance to actinomycin D in Chinese hamster cells in vitro: cross-resistance, radioautographic, and cytogenetic studies. Cancer Res 30: 1174-1184, 1970 .

2. Gottesman MM: Mechanisms of cancer drug resistance. Annu Rev Med 53: 615-627, 2002.

3. Lage H: ABC-transporters: implications on drug resistance from microorganisms to human cancers. Int J Antimicrob Agents 22: 188-199, 2003.

4. Nobili S, Landini I, Giglioni B and Mini E: Pharmacological strategies for overcoming multidrug resistance. Curr Drug Targets 7: 861-879, 2006.

5. Stuart DD, Kao GY and Allen TM: A novel, long-circulating, and functional liposomal formulation of antisense oligodeoxynucleotides targeted against MDR1. Cancer Gene Ther 7: 466-475, 2000.

6. Holm PS, Scanlon KJ and Dietel M: Reversion of multidrug resistance in the $\mathrm{P}$-glycoprotein-positive human pancreatic cell line (EPP85-181RDB) by introduction of a hammerhead ribozyme. Br J Cancer 70: 239-243, 1994.

7. Kowalski P, Surowiak P and Lage H: Reversal of different drug-resistant phenotypes by an autocatalytic multitarget multiribozyme directed against the transcripts of the $\mathrm{ABC}$ transporters MDR1/P-gp, MRP2, and BCRP. Mol Ther 11: 508-522, 2005.

8. Nieth C, Priebsch A, Stege A and Lage H: Modulation of the classical multidrug resistance (MDR) phenotype by RNA interference (RNAi). FEBS Lett 545: 144-150, 2003.

9. Stege A, Priebsch A, Nieth C and Lage H: Stable and complete overcoming of MDR 1/P-glycoprotein-mediated multidrug resistance in human gastric carcinoma cells by RNA interference. Cancer Gene Ther 11: 699-706, 2004.

10. Lage H: Potential applications of RNA interference technology in the treatment of cancer. Future Oncol 1: 103-113, 2005.

11. Brummelkamp TR, Bernards R and Agami R: A system for stable expression of short interfering RNAs in mammalian cells. Science 296: 550-553, 2002.

12. Curcio LD, Bouffard DY and Scanlon KJ: Oligonucleotides as modulators of cancer gene expression. Pharmacol Ther 74: 317-332, 1997.

13. Dietel M, Arps H, Lage $\mathrm{H}$ and Niendorf A: Membrane vesicle formation due to acquired mitoxantrone resistance in human gastric carcinoma cell line EPG85-257. Cancer Res 50: 6100-6106, 1990.

14. Lage $H$ and Dietel M: Multiple mechanisms confer different drug-resistant phenotypes in pancreatic carcinoma cells. J Cancer Res Clin Oncol 128: 349-357, 2002.

15. Lieber A and Kay MA: Adenovirus-mediated expression of ribozymes in mice. J Virol 70: 3153-3158, 1996.

16. Bett AJ, Haddara W, Prevec L and Graham FL: An efficient and flexible system for construction of adenovirus vectors with insertions or deletions in early regions 1 and 3. Proc Natl Acad Sci USA 91: 8802-8806, 1994.

17. McGrory WJ, Bautista DS and Graham FL: A simple technique for the rescue of early region 1 mutations into infectious human adenovirus type 5. Virology 163: 614-617, 1988.

18. Graham FL and Prevec L: Adenovirus-based expression vectors and recombinant vaccines. Biotechnology 20: 363-390, 1992.

19. Aleman C, Annereau JP, Liang XJ, Cardarelli CO, Taylor B, Yin JJ, Aszalos A and Gottesman MM: P-glycoprotein, expressed in multidrug resistant cells, is not responsible for alterations in membrane fluidity or membrane potential. Cancer Res 63: 3084-3091, 2003.

20. Tuschl T: Expanding small RNA interference. Nat Biotechnol 20: 446-448, 2002. 
21. Siolas D, Lerner C, Burchard J, Ge W, Linsley PS, Paddison PJ, Hannon GJ and Cleary MA: Synthetic shRNAs as potent RNAi triggers. Nat Biotechnol 23: 227-231, 2005.

22. Danthinne $X$ and Imperiale MJ: Production of first generation adenovirus vectors: a review. Gene Ther 27: 1707-1714, 2000.

23. Lee NS, Dohjima T, Bauer G, Li H, Li MJ, Ehsani A, Salvaterra P and Rossi J: Expression of small interfering RNAs targeted against HIV-1 rev transcripts in human cells. Nat Biotechnol 20: 500-505, 2002.

24. Miyagishi M and Taira K: U6 promoter-driven siRNAs with four uridine 3' overhangs efficiently suppress targeted gene expression in mammalian cells. Nat Biotechnol 20: 497-500, 2002.

25. Paul CP, Good PD, Winer I and Engelke DR: Effective expression of small interfering RNA in human cells. Nat Biotechnol 20: 505-508, 2002.

26. Ilves H, Barske C, Junker U, Bohnlein E and Veres G: Retroviral vectors designed for targeted expression of RNA polymerase III-driven transcripts: a comparative study. Gene 171: 203-208, 1996.

27. Jacque J-M, Triques K and Stevenson M: Modulation of HIV-1 replication by RNA interference. Nature 418: 435-438, 2002.

28. McManus MT, Petersen CP, Haines BB, Chen J and Sharp PA: Gene silencing using micro-RNA designed hairpins. RNA 8: 842-850, 2002.
29. Materna V, Stege A, Surowiak P, Priebsch A and Lage H: RNA interference-triggered reversal of ABCC2-dependent cisplatin resistance in human cancer cells. Biochem Biophys Res Commun 348: 153-157, 2006.

30. Priebsch A, Rompe F, Tönnies H, Kowalski P, Surowiak P, Stege A, Materna V and Lage H: Complete reversal of ABCG2depending atypical multidrug resistance (MDR) by RNA interference in human carcinoma cells. Oligonucleotides 16: 263-274, 2006.

31. Elbashir SM, Harborth J, Lendeckel W, Yalcin A, Weber K and Tuschl T: Duplexes of 21-nucleotide RNAs mediate RNA interference in cultured mammalian cells. Nature 411: 494-498, 2001.

32. Harborth J, Elbashir SM, Bechert K, Tuschl T and Weber K: Identification of essential genes in cultured mammalian cells using small interfering RNAs. J Cell Sci 114: 4557-4565, 2001.

33. Kretschmer-Kazemi Far R and Sczakiel G: The activity of siRNA in mammalian cells is related to structural target accessibility: a comparison with antisense oligonucleotides. Nucleic Acids Res 31: 4417-4424, 2003. 